\title{
Construction Pathway of Harmonious Campus Culture in the Local Higher Vocational Colleges
}

\author{
Jianhong Li, Qi He \\ Department of Common Courses, Leshan Vocational and Technical College, Leshan, Sichuan, China
}

\begin{abstract}
Harmonious campus culture in local higher vocational college require material culture to cultivate talents through the environment, operating culture is harmonious and high-efficiency, spiritual culture is enrich and healthy. Among them, the school material culture is the foundation and the carrier of local higher vocational college campus culture, operating culture is the operating mechanism of campus culture in local higher vocational college, spiritual culture is the core and main part of campus culture in higher vocational colleges. Construction pathway a harmonious campus culture in higher vocational colleges: highlight the locality, vocation and technicality, new major must be trialed, the new campus layout is reasonable, consciousness of achieving mastery through a comprehensive study and publicity, strengthen the education of strive for the best, introduce top talent, advocate positive culture, do well in in scientific research, propose for the new campus construction, class is harmonious and so on.
\end{abstract}

Keywords-local higher vocational colleges, harmonious campus culture, pathway

\section{和谐校园文化在地方高职院校的构建路径}

\author{
李剑虹何琦 \\ 乐山职业技术学院公课部, 乐山, 四川, 中国
}

\begin{abstract}
摘 要 地方高职院校的和谐校园文化要求物质文化能 “环境育人”, 运行文化协调、高效, 精神文化充实、健康向上。其中, 学校物质文化是地方高职院校校园文化的基础和载体, 运行文化是地方高职院校校园文化的运行机制, 精神文化是地方高职院校校园 文化的核心和主体。地方高职院校构建和谐校园文化的路径: 突出地方性、职业性、技术性, 新专业要试运行, 新校区布局合理, 要 有融会贯通和宣传的意识, 加强力争上游的教育, 引进高端人才, 倡导正效应文化, 搞好科研, 为新校园建设出谋献策, 课堂和谐等。
\end{abstract}

关键词 地方高职院校, 和谐校园文化, 路径

地方高职院校的校园文化也和其他高校一样，它包括 三部分，即学校物质文化、运行文化、精神文化。其中， 学校物质文化是地方高职院校校园文化的基础和载体，运 行文化是地方高职院校校园文化的运行机制, 精神文化是 地方高职院校校园文化的核心和主体。

\section{1. 让物质文化能够起到“环境育人”的作用}

物质文化对身在其中的学生起到 “环境育人” 的作用, 是地方高职院校校园文化的基础, 其建设状况在一定程度 上直接影响着和谐校园文化的质量和整体水平。物质文化 建设, 既是和谐校园文化建设的重要途径和载体, 又是推 进和谐校园文化建设的必要前提和条件。

地方高职院校构建和谐校园文化要利用劳模雕塑大力
加强力争上游的教育。最近 $1 、 2$ 年入学的 90 后大学生, 普 遍存在上进心不强的倾向。究其原因, 除了独生子女缺乏 家庭内部兄弟姐妹的竞争, 打游戏时的激烈竞争致使看淡 了学习、生活和社会竞争等以外, 可能还有中小学思想政 治理论在中高考被边缘化的原因。对此, 除了要求中小学 的思想政治理论也要从小抓起以外, 那就是地方高职院校 必须要补课, 加大力争上游教育力度。如在学校人流集中 处, 搞一些高大醒目, 形成较大规模的励志人生的名人名 言和同学们自己的励志感言, 以起到震撼人心、主导思想 观念的强大作用。一个人只要有积极向上的心态, 成才就 会事半功倍。所以, 磨刀不误砍柴功, 在学生学习成才的 各个阶段加大思想政治教育的力度, 不仅不会影响他们成 才, 反而还有莫大的帮助。另外, 还可以有各种类型的文 
娱演出、诗歌朗诵, 潜移默化地予以励志教育, 也可以在 校园要道而醒目的地方立一些牌子, 牌子上写上诸如 “最 贫的是无才, 最贱的是无志”、“技能再多不压身” 等。行 业标兵的塑像 (事迹) 青立在校园的适当位置, 如南丁格 尔的塑像 (事迹) 靑立在护理专业校园区, “从机修工到旅 游公司经理 李明” 和 “马达维修大王 李文山” 的塑像 (事 迹) 真立在机电专业校园区, “新一代服务标兵、劳动模范 周林芝” 的塑像 (事迹) 毒立于财经专业的校园区, 汽车 “车间调整工 王涛” 的塑像 (事迹) 瞋立于汽电专业的校 园区, “党的十五大代表 吴捷” 的塑像 (事迹) 真立于经 济、商贸专业校园区, “公司生产计划部的副部长 明青” 的塑像 (事迹) 毒立于工商管理专业校园区, “微笑天使 王 冬茹” 的塑像 (事迹) 青立于旅游服务专业校园区、“企 业家和饲养专家 陈阿玲” 和 “玉米良种专家李登海” 的塑 像 (事迹) 青立于农业专业校园区、“影楼老板兼化妆师 吴 莉” 的塑像 (事迹) 矗立于美术专业校园区 (以上人物和 事迹见: 唐凯麟 蒋乃平《职业道德与职业指导》, 高等教 育出版社2001年版)。再如, 古代老中医给弟子的两件礼物 的塑像 (说明) 毒立于护理专业校园区 (见: 朱力宇 张伟 《职业道德与法律》, 高等教育出版社2009年版)。又如, “打算与计算机做终生朋友的咏梅” 的塑像 (事迹) 真立 于计算机专业校园区, 徐虎、海尔的口号和服务承诺、小 林、年景林、郭秀明、河马口隧道五姐妹、班主任朱老师、 全国劳模李黄胥、东汉杨震慎独拒收十金、吴天祥、邱娥 国、李素丽、罗健夫、蒋筑英、张飞绣花、下岗职工庄红 卫、从中专生到大专生再到硕士研究生的潘等等的塑像 (事 迹) 可以有选择地量立于地方高职院校的公共区域（以上 人物和事迹见: 唐凯麟 蒋乃平《职业道德与职业指导》, 高等教育出版社2001年版)。另外, 金晶、全国劳模张秉贵、 铁人王进喜、全国劳模刘怀玉、送快件的小陈、升为财物 总管的小胡、全国劳模许振超、“全国高级技师” 陆琴、 送信员王顺友、全国职工职业道德 “十佳标兵” 邓红英、 卫校实习生丁茹、全国 “技术能手” 邓建军、提醒 “台阶” 的阿霞等的塑像 (事迹) 可以有选择地責立于地方高职院 校的公共区域 (以上人物和事迹见: 朱力宇 张伟《职业道 德与法律》, 高等教育出版社2009年版)。

地方高职院校新旧校区协调、衔接要科学合理。有的 地方高职院校还处于多校合并的初始状态, 校区分散, 而 新校区建设又还不可能马上建成。如果还有 $3 、 5$ 年都不能 建成新校区, 实现搬迁, 而现有教育教学生活设施又不太 理想的话, 那就可以考虑适当改造之, 以适应需要。新校 区的修建, 在不违背科学发展的前提下, 修得紧凑一点, 系部之间不要有围墙, 以便于教育教学生活设施的共同使 用, 也便于学生把各科、各种知识、各种能力等的融会贯
通, 还便于培养学生人际关系在正常交往前提下的和谐相 处的能力。

地方高职院校构建和谐校园文化要积极引进高端人 才, 除了积极引进高端专业技术人才, 尤其要引进高端管 理人才。高端管理人才就是地方高职院校的主要领导。因 为, 当前大部分地方高职院校都是过去的中专校升级、合 并而来, 在办学指导思想、办学理念、办学定位、人才培 养模式、管理体制、治校理念等方面可能还停留在中专阶 段, 中专色彩较浓, 或者还在中专与大学之间徘徊。而从 其他行业、部门和其他具有示范性的地方高职院校引进一 些高端管理人才, 就可以带来新思想、新观念和其他地方 高职院校的成功经验, 从而使所述地方高职院校在示范院 校的申请和办学层次的升级中取得成功。同时, 地方高职 院校也要大力挖掘、培养、使用自己的本校人才。

另外, 可以用职业岗位命名校园内部的楼堂馆所、道 路和景观等。如, 护士楼、护理路、技工喷泉等, 以此强 化学生的专业思想和职业理想。

\section{2. 运行文化协调、高效}

运行文化的基础是组织机构, 核心是规章制度。所以, 运行文化也可以称为制度文化。

组织机构需要科学合理, 职责明确, 既有分工又有合 作, 尽量避免相互推诿、扯皮的现象。规章制度要实现科 学与人文和谐统一, 还要建立科学与人文和谐统一的管理 方式, 才能构建地方高职院校和谐校园文化。没有科学的 规章制度来进行严格的管理, 学校正常的教育教学活动就 无法顺利开展; 但同时也要认识到, 片面地强调学校规章 制度的严格性, 就容易出现压抑, 导致教师之间、师生之 间、学生之间人际关系紧张等局面。故此, 地方高职院校 在开展学校管理工作时要科学规范, 同时也应体现人文精 神, 实现地方高职院校管理的人性化、弹性化, 以和谐的 理念和方法激励广大师生员工的主动发展, 构建硬性制度 与人性化管理和谐统一的学校管理模式。规章制度还要体 现一般和个别、普遍和特殊的辩证关系。比如说, 如果 “上 课出勤” 在某一科的总成绩中占 10 分, 一般情况下大部分 学生很重视, 也可能会出现个别的特殊情况, 就是少数以 60 分万岁的学生干脆就不要这 10 分, 而把早退、迟到、旷 课习以为常。对于此就必须要对症下药, 采取非常措施, 就是对这少数人迟到、早退和旷课扣分就不能限于 10 分, 尤其是旷课一节就要扣得他心痛, 旷课两节就要扣得他觉 得承受不起。这也叫一票否决。出勤是关键, 关键就要用 重典。为了让全体学生顺利毕业, 就要防患于未然, 就是 要教育, 要落到实处, 可以把违纪学生的迟到、早退和旷 课情况登记下来, 现场或者尽快让该生本人签字确认, 也 
需要纪检委员、科代表和班长签字确认。实际情况是, 只 要让考勤有问题的学生签字确认了, 基本上就会起到防止 作用。对于起床困难的学生, 要在上课后几分钟就让学生 干部或者同寝室同学给他打电话, 甚至可以让他们亲自去 请起床困难的学生来上课。这样, 就容易让全体学生顺利 毕业。上午最后一节课的最后几分钟, 学生往往要求提前 下课, 甚至有早退去打饭的。对此, 任课教师要态度鲜明 的制止、教育, 还要有登记下来让学生本人和班干部签字 确认, 并与期末成绩联系的管理手段。这些规章制度在施 行以前要先宣传, 先说断后不乱, 讲清楚施行的重要性, 重要性要多与班级利益、学生本人利益联系。

地方高职院校构建校园和谐文化要突出地方性、职业 性、技术性, 形成制度。地方性, 就是实行在省级尤其是 本地党政机关的领导下, 地方政府主办, 相关局主管, 有 关部门配合, 企业及社会参与的办学管理体制; 立足本地, 服务区域经济和社会发展需要, 建成特色鲜明, 结构合理、 品牌专业优势突出, 主要为本地培养急需的实用的高端技 能型人才。学生的社会实践活动和志愿者活动也要以立足 本地, 走出去为补充, 多种方式并存的良好格局。职业性, 就是地方高职院校坚持校企合作, 走政、产、学、研、用 结合的发展道路, 对接产业办专业, 为本地职业岗位输送 合格的生产、管理、服务第一线的高端技能型人才; 学生 所学专业要与工作 (职业) 岗位对口, 专业知识、技能要 以职业岗位所需来引领。技术性, 就是在将学生培养成知 识、能力、素质协调发展并适应地方经济发展需要的高端 技能型专门人才的同时, 要充分认识到技能是学生在校学 习的主要目标, 就业的根本, 职业发展和创业的源泉。学 生技能要一专多能, 才能在就业、工作、创业的时候左右 逢源, 具有良好的发展空间。

地方高职院校构建校园和谐文化在拓展专业文化时, 新办专业一般采取试运行。这种试运行就是在新开设一个 专业之初往往应该先挂靠在运行较好, 尚未饱和的现有专 业, 实行一个班子, 一套人马, 只是新增一个牌子而已。 试运行的期限以 $3--5$ 年为好, 以便有足够时间予以综合 考察。注意, 试运行的专业的师资队伍应该以外聘为主, 自有为辅。到一定时间以后, 如果发展前景看好, 确有必 要单列, 那才大量招兵买马, 自成一家。真的发展到了这 种良好状态, 师资队伍就应该以自有为主, 外聘为辅了。 这样, 既可以避免新办专业可能前景不妙而导致人力物力 的浪费, 也进退自如、机动灵活, 能更好地适应市场经济 规律所要求的优胜劣汰的需要。新设专业应该要有充分论 证, 论证期以半年为佳。

\section{3. 精神文化充实、健康向上}

精神文化是校园文化的核心和本质, 狭义的校园文化 主要就是指精神文化。所以, 构建和谐精神文化是地方高 职院校构建和谐校园文化的重中之重。

地方高职院校的领导和教职员工要有融会贯通的意 识, 然后在课堂上, 在学生面前起到潜移默化的作用。如 果没有融会贯通, 学的再多也无用, 就是属于读死书。融 会贯通搞好了, 可以使觉得过时、无用的知识派上用场; 融会贯通搞好了, 学校就会成为一个融洽、温馨、和谐的 大家庭, 有利于各种人才的成长和发展; 融会贯通搞好了, 创新就会水到渠成, 蔚然成风, 因为融会贯通需要创新, 创新才能融会贯通。在融会贯通中, 思想政治教师应该走 在前面, 因为思想政治理论本身就具有高度概括性, 是能 够统领各科的科学, 尤其是思想政治理论中的辩证唯物主 义是科学的世界观和方法论, 是对各科知识的高度概括和 总结, 是各科知识融会贯通的结晶。

地方高职院校构建和谐校园文化要注意宣传。地方高 职院校大部分是过去的中专校合并而来, 地方群众对过去 的中专校熟悉, 但是对现在合并后的总称呼和系部称呼, 以及各系部与过去中专校的对应关系还知之甚少。宣传方 式可以有教职员工和学生的各种活动, 如社会实践, 社会 服务, 志愿者行动, 访贫问苦, 支教支边支农等的时候不 影响主题的适可而止的宣传; 还可利用学校校车的宣传功 能; 做好在地方报刊杂志、电视台的宣传等。

地方高职院校构建和谐校园文化要大力倡导正效应文 化。正效应文化, 主要包括社会主义核心价值体系、做四 有公民, 全面发展, 力争最好, 不断更好, 精益求精等。 这样, 才会出现: 学生德智体美劳全面发展, 力争三好, 力争上游; 教师教书育人, 为人师表; 后勤服务育人, 保 障有力; 行政和辅导员管理育人, 以理服人。教育要科学 化、规范化。正效应文化的反面是负效应文化, 就是一些 不良言行, 如上课玩手机, 说话, 迟到早退等不良现象。 对具有典型的负效应文化的人、事、言论, 要说服教育。 例 1 , 对某个班级某个学生在遇到交通事故安全方面的教 育: 在有烦恼的时候、悲痛的时候、忙的时候, 有病或疲 劳致使头昏脑胀视线模糊的时候…… 总之, 只要是你上 了街或者在公路上, 就要忘记这一切的一切, 把安全放在 第一位, 要眼观六路, 耳听八方, 过马路的时候要一看二 慢三通过。天有不测风云, 人有旦夕祸福, 小心驶得万年 船。如果有学生要去探望某个同学因为车祸受伤, 还可以 说, 要把老师和同学们的关心、关爱转告她和她的的亲人, 还要了解一下车祸情况, 肇事方受到惩罚没有? 回来的时 候, 通报一下, 让大家吸取经验教训。如果肇事方还没有 受到惩罚, 大家可以提供道义和法律支援。这些教育可以 
通过开诸葛亮会收集最佳教育方案。例 2 , 关于大学生谈恋 爱的问题, 可以这样教育: 有一种说法叫 “既不提倡, 也 不反对”! “不提倡” 是肯定的, 对恋爱不会像学习好、思 想好、卫生好、写得好、文娱演出好、运动会跑得好等, 不仅提倡, 还要给奖励, 却从来没有那一个学校有恋爱奖。 而 “不反对” 就不一定了, 如果恋爱双方处理得好, 有利 于学习、团结、健康、纪律、校风班风等, 就不反对! 如 若不然, 就要反对! 通过这些教育可以让正效应文化战胜 负效应文化, 让和谐校园文化走上正确的轨道。

地方高职院校构建和谐校园文化要搞好科研。大部分 地方高职院校从中专校合并而来, 科研方面还是一个比较 薄弱的环节。关于科研, 要鼓励、引导。鼓励, 就是要有 激励政策。引导, 就是要提供各研究方向的核心期刊和一 般期刊的基本情况, 一个比较好的办法就是征订这些期刊, 并请那些编辑培训自己的老师和科研人员。

为新校园建设出谋献策。许多地方高职院校是从过去 数个国家级重点中专合并升级而来, 校园还比较分散, 几 乎都遇到一个新校园建设的共同问题, 也都遇到拆迁难的 问题。对于拆迁难的问题, 地方高职院校的师生员工可以 在地方政府主要负责拆迁的基础上, 尽量出点子, 让拆迁 来得顺利一些。在将要拆迁以前, 地方高职院校的师生员 工可以通过各种途径了解拆迁户的思想倾向、成员构成和 就业等基本情况。这种了解, 可以是亲自登门拜访, 也可 以是通过自己的亲朋好友, 还可以是通过三轮车和出租车 师傅等形式。尤其是了解拆迁户的思想倾向, 比如在拆迁 计划出台, 但是还没有实施时, 可以通过各种途径予以了 解, 然后给地方拆迁办提建议。此时听得最多的可能是 “上 面给了那么多钱”, 认为拆迁费太少了。对于这些说法, 当 时就可以说: 不要看到学校是人山人海, 其实是一个大量 消费和支出的地方, 一个学生至少需要 8 个地方来安顿, 就 是每一个学生都要有上课的地方、睡觉的地方、吃饭的地 方、上网的地方、运动的地方、自习的地方、借书阅览的 地方和实训的地方等。地方高职院校可以配合地方政府想 尽千方百计, 直接或者间接地与钉子户接触, 邀请他们到 学校参观、座谈, 可以欢迎他们的子女就读自己的地方高 职院校, 并在政策允许的情况下, 适当予以照顾等。同时, 也可以直接或者间接地告诉这些钉子户, 几百户都搬迁了, 现在就只有少数房屋孤零零地仁立在空旷的荒野中, 过去 的邻居和喧器繁荣已经不在, 物是人非。还可以告诉钉子 户, 你们少数人阻挡着了我们上万学生的成才计划。这些 可以为今后的行政和法律拆迁打下良好的基础。

努力实现课堂和谐。地方高职院校是高端技能型专门
人才的摇篮, 培养这些人才的形式主要还是课堂教学。课 堂教学是培养人才的主体和重要环节, 而课堂和谐是我们 教育工作者所期盼的, 和谐的反义词是动乱, 而介于和谐 和动乱之间的是失调状态。所以课堂状态可以初步分为动 乱状态、失调状态、和谐状态三种。动乱状态就是有下方 位走动, 追逐打闹、争吵, 甚至有和老师争吵的, 课堂像 闹市, 而且有三人及其以上逃课的, 教学秩序受到了严重 冲击, 教学任务根本无法完成。这在文化大革命期间常见, 现在比较少, 基本上没有。对于这个状态, 做为教育工作 者, 为了校园的稳定和谐, 必须千方百计克服, 坚决不允 许出现这种状态。失调状态就是有一、两个人逃课, 还有 睡觉的, 开小差的, 看课外书的, 做白的, 有和老师顶嘴 的, 时不时的要招呼纪律。在这种状态下课堂纪律受到了 影响, 教学任务很难完成。为了校园的稳定和谐, 也必须 克服, 尽量防止出现这种状态。和谐状态就是没有逃课, 没有睡觉, 没有开小差, 没有看课外书, 没有做白的, 也 没有和老师顶嘴的, 而是师生互动。老师讲时, 没有违纪 干扰, 就能够全身心地进入思索式的良好的讲课状态; 学 生听得专心、忘情, 其思维、表情随着老师的讲解而展开、 起伏, 不时有插话给老师讲下半句的, 时而还爆发出欢快 的笑声, 其乐融融。学生发言、朗诵、动起来的时候能够 吸引全班其他同学的目光, 老师也觉得轻松愉快、欣慰、 满意。老师在愉快中讲、组织、倾听; 学生在愉快中学、 动、思考。在这种和谐状态下, 课堂秩序好, 课堂气氛浓 郁, 老师轻轻松松地就完成了教学任务, 学生也在愉快的 氛围中学到了知识, 增强了能力, 达到教学目的, 从而使 学生尽快成才。课堂教学尽量采用仿真性极强的项目化教 学。

\section{参考文献(References)}

[1] Guojie Luo, Weidong Xia, Kailin Tang, etc.:'Ideology and moral cultivation and law foundation, Higher Education Press, 2010 revision.

[2] Shuqing Wu, Zhanan Chen, Keqin Tian, etc.:"Introduction of Mao ze-dong thought and theoretical system of socialism with Chinese characteristics", Higher Education 2010 revision.

[3] Kailin Tang and Naiping Jiang:'Occupation moral and occupation guidance", Higher Education Press, 2001.

[4] Liyu Zhu and Wei Zhang:"Occupation morals and law", High Education Press, 2009. 